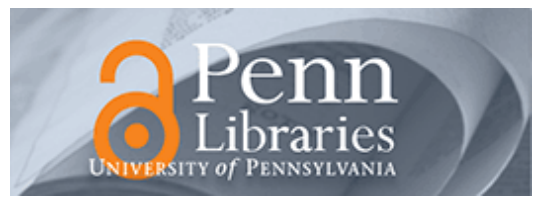

University of Pennsylvania

ScholarlyCommons

$1-16-2020$

\title{
Are Private Kindergartens Really Better? Examining Preschool Choices, Parental Resources, and Children's School Readiness in Ghana
}

\author{
Luca Pesando \\ McGill University \\ Sharon Wolf \\ University of Pennsylvania,wolfs@upenn.edu \\ Jere $\mathrm{H}$. Behrman \\ University of Pennsylvania \\ Edward Tsinigo \\ Innovations for Poverty Action
}

Follow this and additional works at: https://repository.upenn.edu/gse_pubs

Part of the Curriculum and Instruction Commons, Developmental Psychology Commons, and the Early Childhood Education Commons

\section{Recommended Citation}

Pesando, L., Wolf, S., Behrman, J. H., \& Tsinigo, E. (2020). Are Private Kindergartens Really Better? Examining Preschool Choices, Parental Resources, and Children's School Readiness in Ghana. Comparative Education Review, 64 (1), 107-136. http://dx.doi.org/10.1086/706775 


\title{
Are Private Kindergartens Really Better? Examining Preschool Choices, Parental Resources, and Children's School Readiness in Ghana
}

\author{
Abstract \\ Low-cost private schools are expanding across sub-Saharan Africa and are often perceived by parents to \\ be of better quality than public schools. This article assesses the interplay between kindergarten (or \\ preschool) choice, household resources, and children's school readiness in Ghana. We examine how child, \\ household, and school characteristics predict private versus public kindergarten attendance and whether \\ household characteristics are associated with school readiness beyond preschool selection. Using a \\ geospatial-identification strategy to account for observed and unobserved determinants of preschool \\ choice, we find that parental investments-including number of books at home and caregiver help with \\ homework-predict both private-preschool selection and start-of-year child outcomes beyond their \\ influence on preschool choice. We take this evidence as suggesting that investments in children support \\ learning beyond simply selecting the presumed best preschool type. We also find independent \\ associations between attending private preschool and one-year changes in early literacy scores. The \\ findings contribute knowledge to the literature on the recent expansion of preschool education in sub- \\ Saharan Africa and globally and shed new light on the role of private-preschool attendance in early \\ academic skill development.

\section{Keywords} \\ preschool quality, Sub-Saharan Africa, Ghana, preschool choice, school readinessparental school choice

\section{Disciplines} \\ Curriculum and Instruction | Developmental Psychology | Early Childhood Education | Education
}




\title{
Are Private Kindergartens Really Better? Examining Preschool Choices, Parental Resources, and Children's School Readiness in Ghana
}

\author{
LUCA MARIA PESANDO, SHARON WOLF, JERE R. BEHRMAN, AND EDWARD TSINIGO
}

\begin{abstract}
Low-cost private schools are expanding across sub-Saharan Africa and are often perceived by parents to be of better quality than public schools. This article assesses the interplay between kindergarten (or preschool) choice, household resources, and children's school readiness in Ghana. We examine how child, household, and school characteristics predict private versus public kindergarten attendance and whether household characteristics are associated with school readiness beyond preschool selection. Using a geospatial-identification strategy to account for observed and unobserved determinants of preschool choice, we find that parental investments - including number of books at home and caregiver help with homework-predict both private-preschool selection and start-of-year child outcomes beyond their influence on preschool choice. We take this evidence as suggesting that investments in children support learning beyond simply selecting the presumed best preschool type. We also find independent associations between attending private preschool and oneyear changes in early literacy scores. The findings contribute knowledge to the literature on the recent expansion of preschool education in sub-Saharan Africa and globally and shed new light on the role of private-preschool attendance in early academic skill development.
\end{abstract}

\section{Introduction}

Nations across sub-Saharan Africa have recently made significant strides toward meeting the objective of free universal basic education (United Nations 2000) and are now focusing on attaining quality educational systems (United Nations 2015). As demand for education, including preschool education, has grown, concerns about low learning levels have been raised (Britto et al. 2011). Across low- and middle-income countries (LMICs) as diverse as Ghana, Kenya, India, Nigeria, and Pakistan, the private sector has responded more quickly than the public sector to increased demand by providing

Pesando acknowledges financial support from the School of Arts and Sciences at the University of Pennsylvania and from the Fulbright Commission. We thank the UBS Optimus Foundation and the World Bank Strategic Impact Evaluation Fund (SIEF) for direct support for the project for which these data were collected. We also thank the Global TIES for Children Center and NYU Abu Dhabi Research Institute for providing intramural support to Wolf during the development of this study. Finally, we wish to thank J. Lawrence Aber for providing feedback on a previous version of this essay.

Received July 19, 2018; revised April 7, 2019, July 3, 2019, and August 5, 2019; accepted August 23, 2019; electronically published January 16, 2020

Comparative Education Review, vol. 64, no. 1.

(C) 2020 by the Comparative and International Education Society. All rights reserved.

0010-4086/2020/6401-0006\$10.00 
expanded educational services at both pre-primary and primary levels (Tooley et al. 2005; Oketch et al. 2010; Wamalwa and Burns 2018). A large majority of these private schools charge low fees and cater to low-income families, and they struggle to cover their costs (Baum et al. 2018). Yet parents often perceive them to be better quality than public schools (Dixon and Tooley 2012; Zuilkowski et al. 2018), contributing to their growth (e.g., Nishimura and Yamano 2013; Bidwell and Watine 2014).

Early learning skills form the foundation of children's learning trajectories. High-quality early childhood education (ECE) programs can strengthen children's skills prior to primary school entry (Behrman et al. 2014; Berlinski and Schady 2015), and parents across sub-Saharan Africa increasingly agree with this perspective (Bidwell and Watine 2014; Kabay et al. 2017). With the expanding role of private preschools, assessing educational quality and learning across public and private sectors is needed, including better understanding the differences between families of children enrolled in private and public preschools and how different elements predict learning outcomes.

This study investigates determinants of private versus public preschool choices, associations between attending private preschools with children's school readiness, and associations of household characteristics with school readiness beyond relations with preschool choices in Ghana. We address the following research questions: (1) Do characteristics of children, their households, and preschool qualities differ between public and private preschools? (2) Which household and preschool characteristics predict private versus public preschool choice? (3) Beyond selection into preschools, do household characteristics contribute to children's school readiness upon preschool entry $(3 a)$ and over one preschool year (3b)? Using direct child assessments across multiple developmental domains at the beginning of the school year (fall) and at the end (spring), we aim to disentangle relative contributions of household characteristics and private preschool choice as determinants of children's early learning.

This study makes several contributions. First, while there are studies on the differences between public and private schools (Tooley et al. 2005; Tooley et al. 2007), school-choice determinants (Glewwe and Patrinos 1999; Alderman et al. 2001; Nishimura and Yamano 2013; Siddiqui 2017), and implications of school choice for learning in LMICs (Cox and Jimenez 1990; Somers et al. 2004; Chudgar and Quin 2012; Singh 2015), existing research focuses mainly on primary and secondary schools. This article presents, to our knowledge, the first study that examines the interplay of these dimensions at the pre-primary level. Ghana offers a unique case study because it has among the highest levels of ECE enrollment in sub-Saharan Africa (UNESCO 2015a) and has incorporated 2 years of pre-primary as part of universal basic education. Second, we examine whether there are independent associations between household characteristics and school readiness beyond preschool-selection channels. Third, we include a 
rich battery of school readiness outcomes spanning multiple developmental domains. Fourth, we use precise GPS coordinates that make it possible to geolocalize preschools and compute between-preschool distances. These data, and an instrumental variable (IV) two-stage least squares (2SLS) estimation, permit a better understanding of preschool choices and assuage endogeneity concerns related to preschool-choice impacts on children's outcomes (Glewwe and Jacoby 1994). GPS coordinates identify neighboring preschools - those not chosen by families - with their associated characteristics, thus providing exogenous variation that plausibly affects preschool choice but not school readiness. Exogenous variation in preschool choice is needed because the latter is determined, inter alia, by observed and unobserved family variables that also affect children's outcomes.

In light of the significant pre-primary school expansion globally, our findings inform the larger literature on private-sector education in LMICs and its implications for ECE policy and practice. Examining interrelations between parental resources and preschool choice, and the extent to which these affect children's school readiness, also sheds light on policy interventions that might lessen disparities that begin early in children's lives.

\section{Background}

Privatization of LMIC Education and the Ghanaian Context

Private education sectors have grown significantly throughout LMICs (Heyneman and Stern 2014). From 1990 to 2010, the share of LMIC students enrolled in private primary schools doubled from 11 percent to 22 percent (Baum et al. 2014). For sub-Saharan Africa, evidence suggests that the elimination of school fees was the main driver of the increase in private schools due to congestion effects in public schools (Dixon and Tooley 2012; Nishimura and Yamano 2013). This rise has been associated with high demand for school places in the face of limited supply of quality governmental schools (Wamalwa and Burns 2018). The majority of private schools were established through community or private initiatives mainly within informal urban settlements.

Ghana is a lower middle-income country, with 27.5 million people, an average life expectancy of 66.6 years, and approximately 25 percent of the population living below the national poverty line (Central Intelligence Agency 2017). Private-sector participation has expanded in Ghana's educational system since the 1990s. Lewis (2013) documented that in Kasoa, one of the fastest-expanding Ghanaian cities, only seven out of 207 schools in 2013 were public, due to fast private-sector response to local communities' needs (e.g., migrants in search of jobs).

Ghanaian private-sector investment in education is tied to three trends. First, the private sector invests in education to compete with governmental schools. Weaknesses in public education, inadequate supplies of public 
education in deprived areas, and better performance of children in private schools underly some of the private sector's rapid expansion (Nsiah-Peprah 2004; OECD 2012). Second, the government's commitment to public-private partnerships in education provides incentives for private-investor involvement in education. For instance, in 2011 the government adopted the National Policy on Public-Private Partnerships to help facilitate building and maintenance of better educational infrastructures, enhance school management, and ultimately deliver higher-quality education. The government facilitates loans to private schools to improve school infrastructure and limits tuition and other fees for private schools that do not receive governmental subsidies. These controls aim to make private education more affordable for the poor but can also have unintended effects, such as causing school proprietors to limit investments in schools and thus educational quality (Patrinos et al. 2009). Third, there has been growth in public partnerships to improve access for underserved children who have difficulty accessing public schools (Akyeampong 2009).

Increased private-sector involvement in education can lead to widespread quality gaps in terms of inputs, processes, and outputs/outcomes, especially at basic school levels. On one hand, private schools on average have more resources (Tooley et al. 2007; UNESCO 2015b) and provide an environment more conducive to learning (Alderman et al. 2001; OECD 2012). Private-school teachers tend to be more engaged in classrooms, are less likely to be absent, and have smaller class sizes (Tooley et al. 2007). On the other hand, private-sector teachers on average have lower qualifications (Tooley 2005), have less experience, participate less in professional development such as in-service training (NsiahPeprah 2004), and receive lower pay and benefits (Härmä 2009; Mbiti 2016).

\section{Effectiveness of Private Preschools on Children's Outcomes and Endogenous Selection}

Despite greater qualifications and pay for public-school teachers, privateschool students academically outperform those in public schools across most LMICs, including Ghana (Nsiah-Peprah 2004; Singh 2014; Muralidharan and Sundaraman 2015; Mbiti 2016). The validity and magnitude of the privateschool "effect" are, however, debated. The private-school advantage may be due to spurious correlations between private-school attendance and unobserved student and family characteristics, such as children's abilities and parental motivation (Altonji et al. 2005). Children who attend private schools may already have higher academic potential or access to complementary educational resources (a form of cultural capital) and more academically enriching parent-children interactions (a form of social capital).

Endogenous selection into private primary schools is evident in sub-Saharan Africa. In Kenya, many poor parents bypass free public primary schools and send their children to fee-based low-cost private schools due to the perception that 
private schools are of a higher quality (Oketch and Ngware 2010). Many parents, including poor parents, are concerned with the quality of education their children receive and also are likely to ensure that the home environment is favorable for their children's learning. Parents often rely on structural features of schools, such as teacher-student ratios, to evaluate quality (Bidwell and Watine 2014; Bassok et al. 2018). For instance, a study on school-choice determinants in rural Kenya found that parents respond to the poor quality of public education - measured by teacher-student ratios - by sending their children to private schools (Nishimura and Yamano 2013). Accounting for such factors, whether observed or not, can remove or dramatically reduce estimated privateschool advantages (Lucas and Mbiti 2014). There is little evidence of whether endogenous selection operates at the pre-primary level, an investigation we carry out by jointly analyzing determinants of preschool choice and children's school readiness.

\section{Ghanian ECE}

Ghana provides an interesting context in which to study patterns, determinants, and consequences of preschool choice. In 2007, its government became the first in sub-Saharan Africa to expand 2 years of pre-primary education - called KG1 (age 4) and KG2 (age 5) - as part of the free and compulsory state educational system. Ghana has the second highest preschool net enrollment rate in sub-Saharan Africa-74.5 percent for 4- and 5-year-olds and the longest preschool life expectancy (UNESCO 2015a). Net enrollment rates in the Greater Accra Region of Ghana - the context of the present study - are among the highest in Africa (89 percent; Bidwell and Watine 2014). Between 2013 and 2015, private preschools increased four times as fast as public ones, largely influenced by greater involvement of parents, churches, and enterprises in funding and managing preschools (Republic of Ghana 2015). Yet, quality remains a concern (Ghana Education Service 2012), and recent estimates show that one-third of preschoolers in Ghana do not meet basic developmental milestones (McCoy et al. 2017).

Research, mainly from high-income societies, has shown that ECE process quality - the nature of children's daily experiences in the classroom, with a broad focus on the social, emotional, physical, and instructional aspects of activities and interactions - is the key driver of learning (Howes et al. 2003). Structural quality refers to regulable resources, such as class sizes, teacherstudent ratios, and teacher training and education (Slot et al. 2015). These resources improve learning outcomes only if they promote process quality (Phillips et al. 2000; Vandell 2004). And despite having better structural quality, a recent study found that private schools had lower process quality in some dimensions (Wolf et al. 2018). 
Household Resources, Parental Investments, and Children's Outcomes

Important studies - mostly United States focused - have shown that both cultural and social capital predict children's educational success (Lareau 1989; Lareau and Weininger 2003). Each form of capital-alongside more traditional forms of capital such as parental human capital - differentially affects cognitive and behavioral outcomes. For instance, social capital is a more salient factor in predicting behavioral outcomes, with greatest support for parentchild discussions and involvement in parent-teacher organizations (McNeal 1999). Parental involvement in the form of cultural capital seems more salient in predicting cognitive outcomes (Lareau and Weininger 2003). These constructs are complex and can be measured in many ways; we include proxies for both and assess their associations with different domains of school readiness. As capital also determines the type of preschool attended, we examine whether associations between capitals and school readiness persist after controlling for preschool selection.

\section{Data and Measures}

Data were collected in September 2015 and June 2016 as part of a one-year, two-wave impact evaluation of teacher in-service training and parentalengagement programs. The study occurred in six of the nine most disadvantaged districts in the Greater Accra Region, ${ }^{1}$ across public and private preschools serving children enrolled in kindergarten aged 4-6 years. Participating preschools $(N=240)$ included all public preschools $(N=108)$ and private preschools randomly selected proportional to the total number of private preschools in each district $(N=132)$. Preschools were randomly assigned to three groups: in-service teacher training (82 preschools), teacher training and parental-awareness programs (79 preschools), and control (79 preschools). This study did not assess intervention impacts (see Wolf et al. 2019) but instead used the data to examine other research questions. ${ }^{2}$

Data on preschool head teachers were collected. If there were more than two KG teachers in schools, two teachers were randomly sampled (one from KG1, one from KG2). ${ }^{3}$ The final sample was $444 \mathrm{KG}$ teachers across 240 preschools. Finally, 15 children ( 8 from KG1; 7 from KG2) were randomly selected from preschool rosters for direct assessments, for a total of 3,435 children. Children's caregivers were contacted via telephone and answered phone surveys providing information about themselves and their household.

\footnotetext{
${ }^{1}$ La Nkwantanang-Madina, Ga Central, Ledzokuku-Krowor, Adenta, Ga East, and Ga South.

${ }^{2}$ We used the data as if they came from a standard survey design following children at two time points.

${ }^{3}$ Most preschools had two KG classrooms separated into KG1 and KG2, though 10 percent had combined KG classrooms. KG1 children entered their first year of kindergarten at baseline assessment, while KG2 children had been in kindergarten for about one year.
} 
Because of difficulties in obtaining correct phone numbers from preschool records, only around 64 percent of children's caregivers were reached. Table A1 (tables A1-A11 are available online) provides comparisons of child characteristics, locales, and preschool-sector status for children with and without caregiver data; the groups were not statistically significantly different on several child outcomes or locales, except for early numeracy and likelihood of attending private preschools, both higher when caregivers were reached (also see Wolf and McCoy 2019). ${ }^{4}$

As we were interested in disentangling relative contributions of preschool choice and household characteristics to children's school readiness upon preschool entrance, we focused on the 1,712 KG1 children. Of these, 219 (12.8 percent) left the study before follow-up. The analytical sample for our analyses hence was 1,493 KG1 pupils. Attrition analyses, presented in table A2, showed that KG1 children missing at follow-up were only marginally different from the 1,493 assessed in both rounds in terms of baseline characteristics.

\section{School Readiness}

We defined children's school readiness as cognitive and socioemotional skills using the International Development and Early Learning Assessment (IDELA), a comprehensive measure of child learning and development designed for use in LMICs. Pisani and colleagues (2018) and Wolf and colleagues (2017) discussed the construction, reliability, and validity of IDELA. This multidimensional measure aligns with governmental standards (Ghana Education Service 2012) and the global educational community (UNESCO and Brookings 2013) to promote holistic child development.

Four domains were assessed: early numeracy, early literacy, socioemotional development, and executive function. In appendix A (apps. A and B are available online) we report analyses using a combined IDELA score computed as the mean of the four components, while in appendix B we discuss how each domain was constructed. Children's domain-specific scores were measured as the average of percentages of correct answers in subtasks. Outcomes included start-of-year scores and changes in scores over one school year (differences between end-of-year and start-of-year scores). Table 1 reports summary statistics and correlations among the four domains. The academic outcomes-literacy and numeracy - have the highest bivariate correlation $(0.7)$, while correlations between other domains are 0.45 . As expected, scores improved over the year across all domains (fig. 1).

\footnotetext{
${ }^{4}$ We have no data on children who did not go to school and cannot investigate caregivers' choices of not sending children to school (approximately 25 percent of children did not go to kindergarten [Ghana Ministry of Education 2016]).
} 
PESANDO ET AL.

TABLE 1

Descriptive Statistics and Correlation Coefficients of School Readiness at Start-of-Year (Fall), End-of-Year (Spring), and Change in Scores between Fall and Spring $(N=1,493)$

\begin{tabular}{|c|c|c|c|c|c|c|}
\hline & Mean & SD & 1 & 2 & 3 & 4 \\
\hline \multicolumn{7}{|l|}{ Start-of-year (fall): } \\
\hline 1. Early numeracy (EN) & .353 & .164 & 1 & & & \\
\hline 2. Early literacy (EL) & .359 & .186 & .687 & 1 & & \\
\hline 3. Socioemotional skills (SE) & .340 & .191 & .359 & .462 & 1 & \\
\hline 4. Executive function (EF) & .428 & .211 & .469 & .462 & .409 & 1 \\
\hline \multicolumn{7}{|l|}{ End-of-year (spring): } \\
\hline 1. Early numeracy (EN) & .500 & .178 & 1 & & & \\
\hline 2. Early literacy (EL) & .541 & .194 & .712 & 1 & & \\
\hline 3. Socioemotional skills (SE) & .484 & .200 & .386 & .454 & 1 & \\
\hline 4. Executive function (EF) & .540 & .191 & .520 & .507 & .398 & 1 \\
\hline \multicolumn{7}{|l|}{ Change } \\
\hline 1. Early numeracy (EN) & .147 & .142 & 1 & & & \\
\hline 2. Early literacy (EL) & .182 & .164 & .304 & 1 & & \\
\hline 3. Socioemotional skills (SE) & .144 & .220 & .158 & .297 & 1 & \\
\hline 4. Executive function (EF) & .112 & .223 & .162 & .218 & .251 & 1 \\
\hline
\end{tabular}

\section{Household Resources and Parental Investments}

Phone surveys with parents collected information on household resources and parental investments, several from the UNICEF Multiple Indicators Cluster Surveys (MICS). First, caregivers estimated the number of children's books in their household (e.g., picture books), one commonly used measure of cultural capital (Xu and Hampden-Thompson 2012) and a common proxy for learning materials in low-resource contexts (Bradley and Putnick 2012; Wolf and McCoy 2019). ${ }^{5}$ Second, we created an index ranging from 0 to 6 of caregiver participation in cognitively stimulating activities with children (activities with child) based on responses to a series of yes/no questions (see app. B) and adapted from the UNICEF MICS module on early childhood development (ECD). Third, we asked the extent to which caregivers or other adults helped [C] with homework over the previous 30 days $(1=$ never, $4=$ regularly). Fourth, we built an index ranging from 0 to 5 for parental involvement in school based on caregivers' reports of whether they or other household adults engaged in specific school-related activities during the last school year (app. B). Activities with the child, help on homework, and parental involvement in school all represent forms of social capital (Bianchi and Robinson 1997; McNeal 1999). Again, note that only around 64 percent of children's caregivers were reached, hence there was a significant amount of missing data on these variables which was imputed using multiple imputation. ${ }^{6}$

\footnotetext{
${ }^{5}$ There is extensive literature on the complexity of concepts such as cultural capital and the issues arising from adopting simple measures such as numbers of books in households (e.g., Sieben and Lechner 2019). Our data set is limited in this respect, and we draw on what we believe is the most appropriate proxy, however simplistic.

${ }^{6}$ Given some differences in the characteristics of children whose caregivers were reached versus those who were not, there is reason to suspect that caregivers who were not reached had, on average,
} 

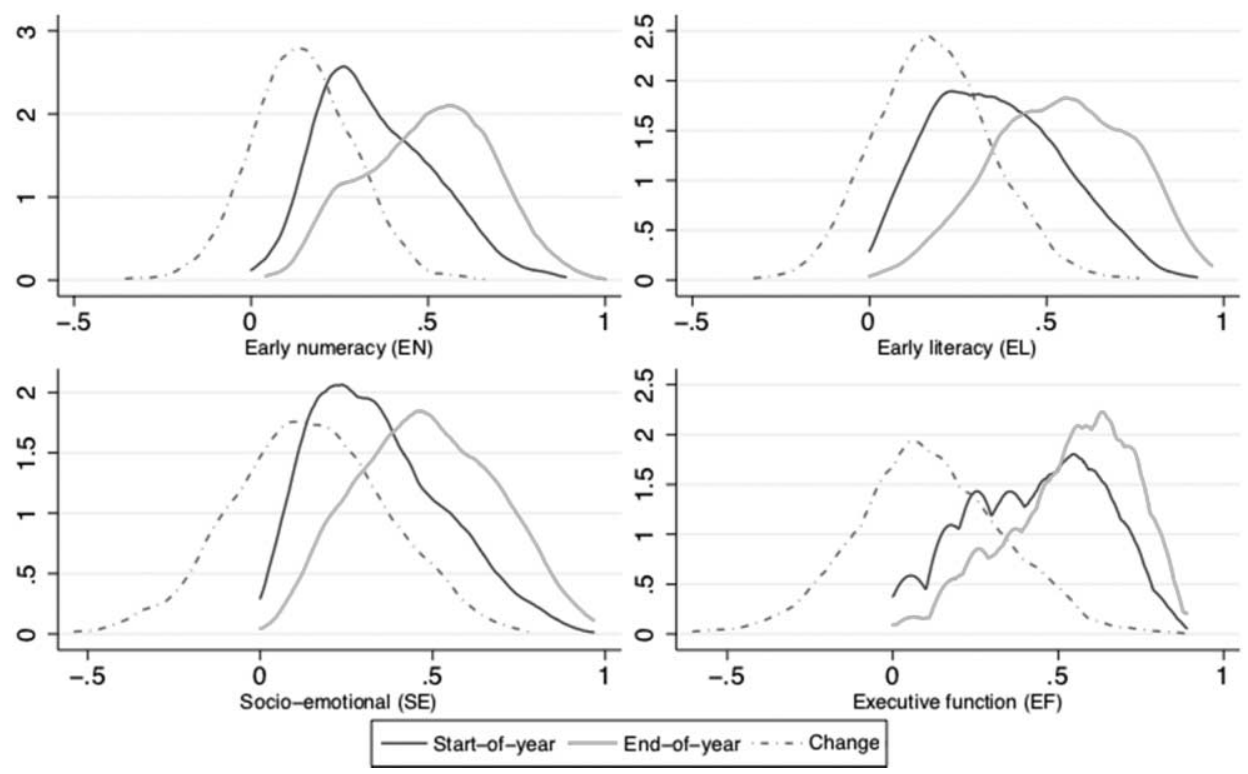

Fig. 1.-Kernel densities at the start of the year (fall) and at the end of the year (spring) and the gain in school readiness (spring-fall) for the four separate domains. A color version of this figure is available online.

\section{Additional Predictors}

We used two measures of household SES: household wealth and caregiver education. In LMICs like Ghana, household wealth is more significant than other measures of household resources (e.g., income, education) in predicting how well children did in school (Filmer and Pritchett 2001). Households with more possessions have higher purchasing power to respond to children's educational resource needs, as they can sell possessions for cash. Furthermore, household wealth provides a stable picture of households' economic health, as assets are accumulated over time and are sources of security against unexpected shocks (Chowa et al. 2013). Household wealth was measured using the Poverty Scorecard for Ghana (Schreiner and Woller 2010), developed using the national 2005-2006 Ghana Living Standards Survey and administered in the census by the Ghana Statistical Service. The scorecard estimates the likelihood that a household had expenditures below a given poverty line by combining 10 indicators (app. B) related to household structure and facilities. Scores on each response were assigned different numerical values and summed, with total scores ranging from 1 to 100 (greater wealth).

lower socioeconomic status. In turn, this might reflect lower parental investments. The summary statistics pertaining to parental investments in this study might thus be overestimated. We acknowledge this as a limitation of this data set, which is nonetheless very rich in other sources of information. 
Primary caregivers were also asked the highest levels of education they attained, coded as a categorical variable with 13 values ranging from "Less than primary" to "Masters/PhD." We created a dummy variable, where $0 \leq$ junior high school ( JHS), and 1> JHS, the completion of which marks the end of the basic education cycle (11 years). Other household-level controls included caregiver age, sex, and marital status (see table 2 for descriptive statistics).

The data set also provided measures of preschool, classroom, and teacher characteristics. To summarize information and minimize the number of variables used, we constructed four resource indices. The preschool resource index ranged from 0 to 14 and was the sum of 14 preschool-inventory components dichotomized (0: absent, 1: present). The classroom resource index ranged from 1 to 9 and was the sum of nine components rescaled to $0-1$. The teacher quality/ motivation index combined information averaged across classrooms and was the sum of four dichotomized components. The head teacher quality index was the sum of two dichotomized components. Correlations among the four indices were small (table A3), suggesting these were distinct constructs. Appendix B describes all the single index components.

\section{Geographic Data}

No information is available to geolocalize households and compute householdschool distances. However, precise GPS coordinates of all preschools were obtained (fig. 2). We used this information to compute distances-in kilometers and walking travel times using Google Maps Distance Matrix API-among preschools to identify a pool of close-enough preschools - using different radiusesof opposite type to the one actually chosen (e.g., public preschools for children enrolled in private preschools). These constitute alternative "choice sets" for households deciding whether to send their children to public or private

TABLE 2

Descriptive Statistics on Child and Household Characteristics $(N=1,493)$

\begin{tabular}{lcccrr}
\hline & Observations & Mean & SD & Minimum & Maximum \\
\hline Child is female (proportion) & 1,493 & .486 & .500 & 0 & 1 \\
Child's age (years) & 1,426 & 4.623 & 1.158 & 2 & 10 \\
Caregiver's age (years) & 1,198 & 37.88 & 8.950 & 18 & 78 \\
Caregiver is female (proportion) & 1,203 & .506 & .500 & 0 & 1 \\
Caregiver's education > JHS & 1,200 & .303 & .459 & 0 & 1 \\
Caregiver is married (proportion) & 1,198 & .780 & .415 & 0 & 1 \\
Wealth (poverty scorecard) & 1,198 & 60.48 & 13.89 & 18 & 92 \\
Number of books at home & 1,146 & 2.837 & 2.681 & 0 & 10 \\
Activities with child (index) & 1,188 & 3.903 & 1.795 & 0 & 6 \\
Help on homework & 1,198 & 3.432 & .871 & 1 & 4 \\
Parental involvement in school (index) & 1,183 & 1.773 & 1.262 & 0 & 5
\end{tabular}

Note.-JHS = junior high school, the completion of which marks the end of the basic education cycle (11 years) in Ghana. 


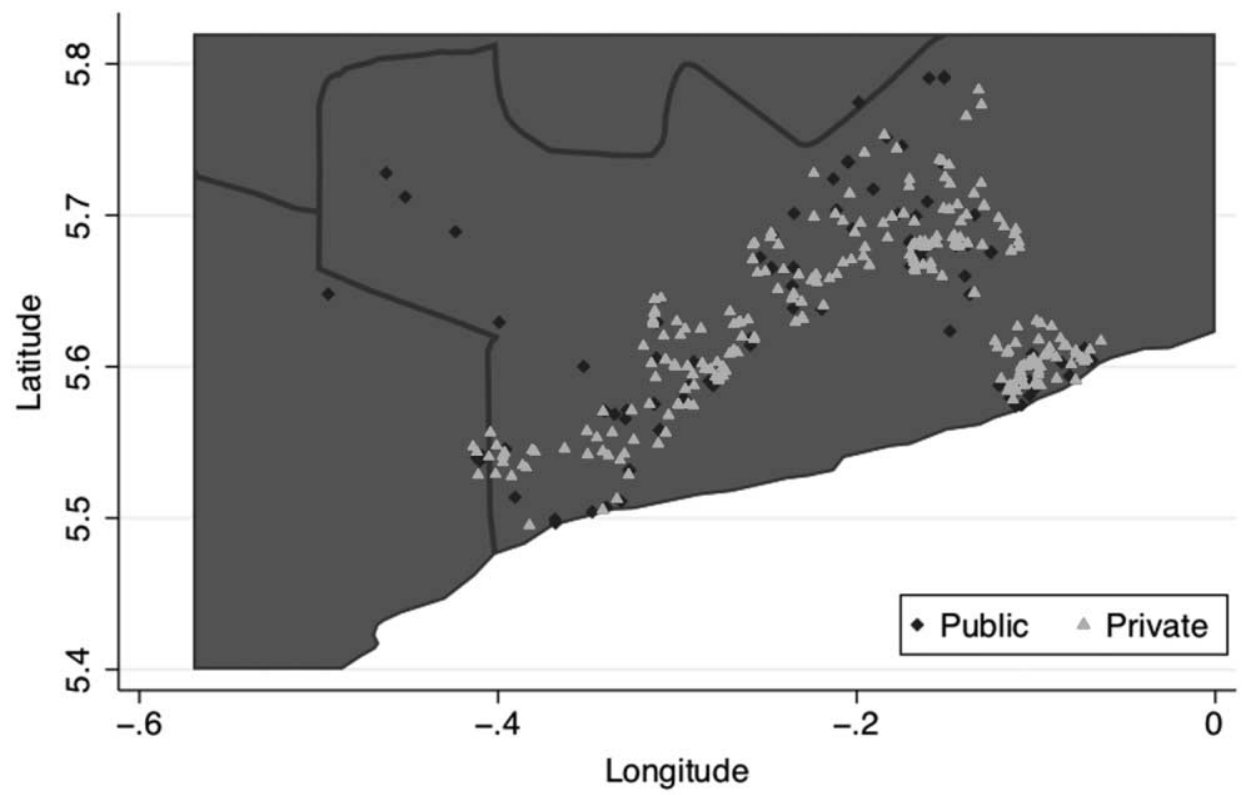

Fig. 2.-Geographical distribution of public and private preschools in the Greater Accra Region sampled in this study. Note: From the Ghana Education Service (GES) Educational Management Information System (EMIS) it is possible to identify 1,998 preschools in the Greater Accra Region, 609 of which are public and 1,389 private. These figures include the sampled preschools for the listing/actual study. A color version of this figure is available online.

preschools. The underlying assumption was that the neighboring preschools were the potential "competitors" for schools actually chosen. ${ }^{7}$

We identified the closest preschool of the opposite type and measured distance in kilometers (mean $1.84 \mathrm{~km}$ ) and walking time to that preschool (mean 22.4 minutes) (table A4). Next, to account for quantity of neighboring preschools, we calculated the number of preschools of the opposite typeexcluding the closest one-and the number of preschools of the same type within a 30-minute radius on foot (mean of 5). ${ }^{8}$ Descriptive statistics and sensitivity analyses using narrower (15-minute) and wider (45-minute) radiuses show analogous results (tables A4, A5). To account for neighboring preschools' qualities, we also created preschool-, classroom-, teacher-, and head teacher-level indices, and included these in the preschool-choice specification described below (eq. [1]). As our research questions concern the choice of a

${ }^{7}$ All public schools were included in the sample, but only subsamples of private schools. Therefore, for children attending private schools we identified close-by schools of the opposite type, while for children attending public schools we only identify close-by private sample schools included.

${ }^{8}$ We used the "gmapsdistance" package in R. We used radiuses for distances $(2 \mathrm{~km})$ and walking time (30 minutes). The correlations were high $(0.93-0.96)$, hence we used only the latter. 
specific type of preschool (public versus private), rather than the choice of a specific preschool (e.g., this private preschool versus a neighboring private preschool), we did not include geospatial information - and associated characteristics - on neighboring preschools of the same type, yet we controlled for their number. Table A6 provides robustness checks using alternative preschoolchoice specifications also including geospatial information and characteristics of neighboring preschools of the same type with varying radiuses.

\section{Methodology}

We examined how public and private kindergartens differed in terms of child, household, and preschool characteristics using $t$-tests for mean differences; importantly, these raw differences might simply reflect selection bias. We then investigated which characteristics predicted private versus public kindergarten choice (PRI) using a linear probability model (LPM) $:^{9}$

$$
\mathrm{PRI}=\operatorname{PRI}\left(\mathrm{HH}, \mathrm{V}_{\mathrm{PRI}}, \mathrm{V}_{\mathrm{PUB}}\right) \text {, }
$$

where $\mathrm{HH}$ is a vector of household characteristics, and $\mathrm{V}_{\mathrm{PRI}}$ and $\mathrm{V}_{\mathrm{PUB}}$ are vectors of preschool (comprising preschool, classroom, teacher and head teacher) characteristics of local private and public preschools, respectively, measured at the start of the year as described in the previous section. We next explored determinants of school readiness upon preschool entrance. As KG1 children at the start of the year generally were new to the basic education system, we hypothesized that school readiness at this point depended exclusively on HH. Importantly, in equation (1), HH is incorporated in the preschool-choice specification, suggesting that part of the associations between household characteristics and school readiness $\left(\mathrm{SR}_{0}\right)$ was related to the extent to which $\mathrm{HH}$ determined preschool choice. We hence explored whether $\mathrm{HH}$ affected $\mathrm{SR}_{0}$ beyond preschool choice (PRI) by estimating:

$$
\mathrm{SR}_{0}=\mathrm{SR}_{0}(\mathrm{HH}, \mathrm{PRI})
$$

using equation (1) as first stage ( $\widehat{\mathrm{PRI}})$ in instrumental variable (IV) 2SLS estimates where the geospatial variables (plausibly exogenous with respect to children's school readiness) served as instruments. The 2SLS approach assuages endogeneity concerns related to unobserved factors - for example, children's abilities, parental motivations, tastes for schooling - that simultaneously affected preschool selection and school readiness. ${ }^{10}$

\footnotetext{
${ }^{9}$ We used LPMs rather than logits or probits because the former is more transparent for 2SLS. The sample means were near 0.5 so there were not issues of nonlinearities near zero and one. Probit specifications delivered similar findings (available upon request).

${ }^{10}$ In the absence of this strategy, which attempts to control for both observed and unobserved determinants of school choice, we would risk attributing to the school type chosen the correlated direct association of the unobserved factors on school readiness.
} 
To assess whether private preschooling affected school readiness over a school year purged of selection effects, we estimated a specification for gain in scores $\left(\mathrm{SR}_{1-0}\right)$, using (1) as the first stage in 2SLS estimates:

$$
\mathrm{SR}_{1-0}=\mathrm{SR}_{1-0}(\mathrm{HH}, \mathrm{PRI})
$$

To summarize, equation (2) provided estimates for what $\mathrm{HH}$ yields beyond PRI for school readiness at the start of the school year, while equation (3) provided estimates for what PRI yields beyond $\mathrm{HH}$ for gains in school readiness over the school year. The use of IV 2SLS in equations (2) and (3) allowed for plausibly causal interpretations under weaker assumptions than required with OLS. In all specifications, standard errors were clustered at the preschool level, and missing covariate values were treated using multiple imputation with 50 imputations. ${ }^{11}$

\section{Results}

Research Question 1: Do Child, Household, and Preschool Characteristics

Differ across Public and Private Preschools?

Table 3 presents means and mean difference tests by preschool type. ${ }^{12}$ Panel A shows mean differences in child characteristics. Kindergarten children in public preschools were older than their counterparts in private preschools (4.9 versus 4.3 years; $P<.01$ ). Children in private preschools, despite being younger, were likely to be more "school ready" on most dimensions of development (except socioemotional skills). These two patterns suggest that parents who send their children to private preschool are more likely to enroll their children on time and to invest in their educational experiences before they begin preschool.

Children's caregivers (panel B) in public preschools were more likely to be older, female, less educated, unmarried or separated, and to live in larger households. Measures of SES, household resources, and parental engagement largely favored children in private preschools. As expected, households that sent their children to public preschools were on average poorer than those who sent their children to private preschools $(52.8$ versus 67.0 on the Poverty Scorecard; $P<.01$ ), and private-school children had access to more cultural capital in the form of books $(3.4$ versus 2.2; $P<.01)$. Parental engagement in

\footnotetext{
${ }^{11}$ We used the Stata "mi impute mvn" command with 50 imputations.

${ }^{12}$ Summary statistics on child and household characteristics were computed using the analytical sample (1,493 KG1 children who completed the assessment at both baseline and follow-up), while descriptive statistics on preschool-, classroom-, and teacher-level characteristics were computed from all baseline data (240 preschools, 314 classrooms, and 444 teachers). The 1,493 children surveyed at baseline and follow-up were in fact nested within 218 schools, not the 240 preschools that constitute the overall baseline sample of schools. Preschool-, classroom-, teacher- and head teacher-level differences in means recomputed on the restricted sample (available upon request) did not significantly differ from those in table 3 .
} 
TABLE 3

Means and Mean Differences Tests in Child, Household, and Preschool Characteristics

\begin{tabular}{|c|c|c|c|c|c|}
\hline & \multicolumn{3}{|c|}{ Mean or Proportion } & \multirow[b]{2}{*}{$P$-value } & \multirow[b]{2}{*}{ Observations } \\
\hline & Public & Private & Difference & & \\
\hline \multicolumn{6}{|l|}{ a. Child $(N=1,493)$} \\
\hline Child is female (prop.) & .48 & .49 & -.007 & .781 & 1,493 \\
\hline Child's age (years) & 4.93 & 4.34 & $.593^{* * *}$ & .000 & 1,426 \\
\hline Early numeracy (EN) & .32 & .38 & $-.063^{* * *}$ & .000 & 1,493 \\
\hline Early literacy (EL) & .32 & .40 & $-.082^{* * *}$ & .000 & 1,493 \\
\hline Socioemotional skills (SE) & .34 & .34 & .001 & .934 & 1,493 \\
\hline Executive function (EF) & .41 & .44 & $-.027^{* *}$ & .013 & 1,493 \\
\hline \multicolumn{6}{|l|}{ b. Household $(N=1,493)$} \\
\hline Caregiver's age (years) & 38.85 & 37.06 & $1.788^{* * *}$ & .001 & 1,198 \\
\hline Caregiver is female (prop.) & .54 & .48 & $.062^{* *}$ & .032 & 1,203 \\
\hline Caregiver's education $>$ JHS & .19 & .39 & $-.200^{* * *}$ & .000 & 1,200 \\
\hline Caregiver is married (prop.) & .71 & .84 & $-.126^{* * *}$ & .000 & 1,198 \\
\hline Household size & 5.77 & 5.08 & $.697^{* * *}$ & .000 & 1,199 \\
\hline Wealth (poverty scorecard) & 52.76 & 67.04 & $-14.28^{* * *}$ & .000 & 1,198 \\
\hline Number of books at home & 2.22 & 3.37 & $-1.148^{* * *}$ & .000 & 1,146 \\
\hline Activities with child (index) & 3.67 & 4.10 & $-.439^{* * *}$ & .000 & 1,188 \\
\hline Help on homework & 3.22 & 3.61 & $-.396^{* * *}$ & .000 & 1,198 \\
\hline Parental involvement in school (index) & 1.49 & 2.01 & $-.523^{* * *}$ & .000 & 1,183 \\
\hline \multicolumn{6}{|l|}{ c. Preschool $(N=240)$} \\
\hline Years preschool has been established & 31.49 & 13.88 & $17.61^{* * *}$ & .000 & 224 \\
\hline Preschool has written rules for staff (prop.) & .49 & .34 & $.145^{* *}$ & .023 & 238 \\
\hline Preschool days per month KG teachers absent & .96 & .52 & $.448^{* * *}$ & .000 & 237 \\
\hline Total KG children in preschool & 79.35 & 41.70 & $37.65^{* * *}$ & .000 & 238 \\
\hline Total KG teachers on payroll & 2.52 & 1.86 & $.662^{* * *}$ & .000 & 238 \\
\hline Teacher-pupil ratio & .04 & .06 & $-.018^{* * *}$ & .000 & 238 \\
\hline Proof of record of teachers' attendance (prop.) & .88 & .74 & $.136^{* * *}$ & .008 & 238 \\
\hline Age of head teacher (years) & 51.62 & 47.52 & $4.100^{* *}$ & .014 & 199 \\
\hline Head teacher has training in ECD (prop.) & .38 & .50 & $-.128^{* *}$ & .049 & 238 \\
\hline Years of experience of head teacher & 4.49 & 6.40 & $-1.911^{* * *}$ & .001 & 225 \\
\hline \multicolumn{6}{|l|}{ d. Classroom $(N=314)$} \\
\hline Teachers per classroom & 1.44 & 1.18 & $.261^{* * *}$ & .000 & 314 \\
\hline Fewer than 25 children per classroom (prop.) & .58 & .76 & $-.183^{* * *}$ & .001 & 314 \\
\hline Books in the classroom & .89 & .95 & $-.062^{* *}$ & .042 & 314 \\
\hline Behavior management index & 1.59 & 1.05 & $.534^{* * *}$ & .000 & 314 \\
\hline Instructional practice index & 1.11 & .89 & $.216^{* *}$ & .029 & 314 \\
\hline \multicolumn{6}{|l|}{ e. Teacher $(N=444)$} \\
\hline Age of teacher (years) & 40.54 & 30.86 & $9.673^{* * *}$ & .000 & 444 \\
\hline Years as a teacher & 6.79 & 6.14 & .649 & .306 & 443 \\
\hline Years as a teacher in current preschool & 2.86 & 3.79 & $-.936^{* *}$ & .011 & 442 \\
\hline Any postsecondary training (prop.) & .95 & .29 & $.656^{* * *}$ & .000 & 444 \\
\hline Any ECD training/exposure (prop.) & .72 & .63 & $.089^{* *}$ & .045 & 444 \\
\hline \multicolumn{6}{|l|}{ f. Indices $(N=240)$} \\
\hline Preschool resource index & 9.95 & 11.18 & $-1.238^{* * *}$ & .000 & 238 \\
\hline Classroom resource index (preschool average) & 7.03 & 7.12 & -.096 & .494 & 233 \\
\hline $\begin{array}{l}\text { Teacher quality/motivation index (preschool } \\
\text { average) }\end{array}$ & 2.84 & & & & 240 \\
\hline Head teacher quality index & .73 & 1.05 & $-.327^{* * *}$ & .001 & 238 \\
\hline
\end{tabular}

NOTE.-ECD = early childhood development; JHS = junior high school; KG = kindergarten; prop. = proportion. Descriptive statistics on preschool, classroom, teacher, and head teacher-level characteristics are computed on all available baseline data, independently of the restriction imposed on the children's sample (KG1 only observed at both baseline and follow-up). If we restrict to this sample, children are nested within 218 preschools rather than 240.

$* P<.10$

$* * P<.05$.

$* * * P<.01$. 
both cognitively stimulating activities (reading books, telling stories, singing songs, helping on homework) and school-related activities (attending PTA meetings or any school-related event) was higher for households who sent their children to private preschools.

Public preschools were significantly older $(31.5$ years versus $13.9 ; P<.01$ ) and more likely to have written rules and codes of conduct than private preschools (panel C). Although teacher absenteeism was reportedly higher in public preschools ( 0.96 days per month versus 0.52 in the private sector; $P<$ $.01)$, public preschools were more likely to have formal systems for tracking absences. Public preschools also had more KG students (79.3 versus 41.7 children per preschool) and teachers on payroll, yet the teacher-student ratio (considered by some to be an important determinant of learning outcomes and an indicator of the overall educational system quality (Jones 2016) was higher in private preschools $(1: 16$ versus $1: 25 ; P<.01)$. Public preschools had slightly older and less experienced head teachers, with significantly lower proportions trained in ECD (0.38 versus $0.50 ; P<.05)$. Teachers in public preschools were also older, yet they (panel E) were more experienced - that is, more likely to possess postsecondary education $(0.95$ versus $0.29 ; P<.01)$ and to be trained in ECD $(0.72$ versus $0.63 ; P<.10)$.

Classroom observational data (panel D) showed that public preschools were more effective in promoting cooperative learning, stimulating classroom interactions, praising children for positive behaviors, and using specific tools to facilitate learning. Overall, the preschool-, classroom-, teacher-, and head teacher-level indices (panel F) suggested that private preschools had significantly better preschool facilities than public preschools (11.2 versus $9.9 ; P<$ .01 ), worse quality in terms of teachers' characteristics (2.4 versus $2.8 ; P<.01$ ), and better-qualified head teachers $(1.0$ versus $0.7 ; P<.01)$.

Research Question 2: Which Household and Preschool Characteristics

Predict Private versus Public Preschool Choices?

We estimated an LPM predicting probabilities of choosing private preschools (eq. [1]), with models sequentially adding sets of predictors (table 4). Model (1) included child characteristics (sex and age); model (2) added household characteristics (caregiver age, sex, education, and marital status; household resources; parental investments); model (3) added school-resources, classroomresources, and teacher- and head teacher-quality indices for the chosen preschools; model (4) added walking times to the closest preschools of the opposite type, and the preschool-, classroom-, teacher-, and head teacher-level indices of those same preschools; model (5) added the number of preschools of the opposite type - excluding the closest one accounted for in model (4) - and the number of preschools of the same type within a 30-minute walk (full specification). We included characteristics of the selected school in the school-choice specification, as this was also in the pool of candidates-hence it is reasonable 
TABLE 4

Preschool-Choice Specification, First-Stage Estimates

\begin{tabular}{|c|c|c|c|c|c|}
\hline Preschool Choice (Private $=1$ ) & (1) & $(2)$ & (3) & (4) & $(5)$ \\
\hline \multicolumn{6}{|l|}{ Child: } \\
\hline Female & $\begin{array}{c}-.010 \\
(.028)\end{array}$ & $\begin{array}{c}-.009 \\
(.023)\end{array}$ & $\begin{array}{c}-.013 \\
(.020)\end{array}$ & $\begin{array}{c}-.024 \\
(.019)\end{array}$ & $\begin{array}{c}-.002 \\
(.016)\end{array}$ \\
\hline Age & $\begin{array}{c}-.110^{* * *} \\
(.016)\end{array}$ & $\begin{array}{c}-.059^{* * *} \\
(.013)\end{array}$ & $\begin{array}{c}-.051^{* * *} \\
(.012)\end{array}$ & $\begin{array}{c}-.050^{* * *} \\
(.011)\end{array}$ & $\begin{array}{c}-.032^{* * *} \\
(.010)\end{array}$ \\
\hline \multicolumn{6}{|l|}{ Household: } \\
\hline Caregiver's age & & $\begin{array}{c}-.004^{* *} \\
(.001)\end{array}$ & $\begin{array}{c}-.003^{* *} \\
(.001)\end{array}$ & $\begin{array}{r}-.002^{*} \\
(.001)\end{array}$ & $\begin{array}{c}-.001 \\
(.001)\end{array}$ \\
\hline Caregiver is female & & $\begin{array}{c}.044 \\
(.028)\end{array}$ & $\begin{array}{l}.045^{*} \\
(.026)\end{array}$ & $\begin{array}{l}.036 \\
(.025)\end{array}$ & $\begin{array}{l}.009 \\
(.021)\end{array}$ \\
\hline Caregiver's education $>$ JHS & & $\begin{array}{l}.019 \\
(.030)\end{array}$ & $\begin{array}{l}.018 \\
(.030)\end{array}$ & $\begin{array}{l}.007 \\
(.026)\end{array}$ & $\begin{array}{c}-.008 \\
(.023)\end{array}$ \\
\hline Caregiver is married & & $\begin{array}{l}.086^{* * *} \\
(.032)\end{array}$ & $\begin{array}{l}.071^{* *} \\
(.029)\end{array}$ & $\begin{array}{l}.076^{* * *} \\
(.028)\end{array}$ & $\begin{array}{l}.032 \\
(.025)\end{array}$ \\
\hline Wealth (poverty scorecard) & & $\begin{array}{l}.016^{* * *} \\
(.001)\end{array}$ & $\begin{array}{l}.013^{* * *} \\
(.001)\end{array}$ & $\begin{array}{l}.011^{* * *} \\
(.001)\end{array}$ & $\begin{array}{l}.008^{* * *} \\
(.001)\end{array}$ \\
\hline Number of child's books at home & & $\begin{array}{l}.010^{* *} \\
(.005)\end{array}$ & $\begin{array}{l}.007^{*} \\
(.004)\end{array}$ & $\begin{array}{l}.006 \\
(.004)\end{array}$ & $\begin{array}{l}.006 \\
(.004)\end{array}$ \\
\hline Activities with child (index) & & $\begin{array}{c}-.022^{* *} \\
(.009)\end{array}$ & $\begin{array}{c}-.017^{* *} \\
(.008)\end{array}$ & $\begin{array}{r}-.013^{*} \\
(.008)\end{array}$ & $\begin{array}{c}-.002 \\
(.007)\end{array}$ \\
\hline Help on homework & & $\begin{array}{l}.032^{*} \\
(.019)\end{array}$ & $\begin{array}{c}.024 \\
(.018)\end{array}$ & $\begin{array}{l}.013 \\
(.016)\end{array}$ & $\begin{array}{l}.008 \\
(.014)\end{array}$ \\
\hline Parental involvement in school (index) & & $\begin{array}{l}.038^{* * *} \\
(.013)\end{array}$ & $\begin{array}{l}.026^{* *} \\
(.012)\end{array}$ & $\begin{array}{l}.018^{*} \\
(.011)\end{array}$ & $\begin{array}{c}.007 \\
(.009)\end{array}$ \\
\hline \multicolumn{6}{|l|}{ Chosen preschool: } \\
\hline Preschool resource (index) & & & $\begin{array}{l}.043^{* * *} \\
(.011)\end{array}$ & $\begin{array}{l}.036^{* * *} \\
(.011)\end{array}$ & $\begin{array}{l}.025^{* *} \\
(.010)\end{array}$ \\
\hline Classroom resource (index) & & & $\begin{array}{r}-.037^{*} \\
(.020)\end{array}$ & $\begin{array}{c}-.011 \\
(.020)\end{array}$ & $\begin{array}{c}-.025 \\
(.017)\end{array}$ \\
\hline Teacher quality/motivation (index) & & & $\begin{array}{c}-.125^{* * *} \\
(.022)\end{array}$ & $\begin{array}{c}-.103^{* * *} \\
(.022)\end{array}$ & $\begin{array}{c}-.068^{* * *} \\
(.019)\end{array}$ \\
\hline Head teacher quality (index) & & & $\begin{array}{l}.065^{*} \\
(.038)\end{array}$ & $\begin{array}{l}.062^{*} \\
(.036)\end{array}$ & $\begin{array}{l}.073^{* *} \\
(.028)\end{array}$ \\
\hline
\end{tabular}


Closest preschool of opposite type:

Time walking to closest preschool of opposite type (minutes)

.000

Preschool resource (index)

Classroom resource (index)

Teacher quality/motivation (index)

Head teacher quality (index)

Set of neighboring preschools (within 30-minute walk)

Number of preschools of opposite type

Number of preschools of same type

\begin{tabular}{|c|c|c|c|c|}
\hline & & .000 & $\begin{array}{c}-.000 \\
(.001) \\
-.033^{* * *} \\
(.012) \\
.003 \\
(.023) \\
.157^{* * *} \\
(.022) \\
-.085^{* *} \\
(.037)\end{array}$ & $\begin{array}{c}(.000) \\
-.031^{* * *} \\
(.011) \\
.003 \\
(.021) \\
.136^{* * *} \\
(.019) \\
-.063^{* *} \\
(.030)\end{array}$ \\
\hline & & & & $\begin{array}{c}-.038^{* * *} \\
(.004) \\
.028^{* * *} \\
(.004)\end{array}$ \\
\hline $\begin{array}{l}36^{* * *} \\
88)\end{array}$ & $\begin{array}{l}-.207 \\
(.139)\end{array}$ & $\begin{array}{l}-.008 \\
(.194)\end{array}$ & $\begin{array}{c}-.029 \\
(.289)\end{array}$ & $\begin{array}{l}.202 \\
(.257)\end{array}$ \\
\hline 493 & 1,493 & 1,493 & 1,493 & 1,493 \\
\hline
\end{tabular}

$\sqrt{0}$

Constant

1,493 1,49

NotE. - Standard errors clustered at the preschool level. JHS $=$ junior high school.

$* P<.10$.

$* * P<.05$
$* * * P<.01$

The closest preschool of the opposite type is excluded, as it already is included above. Specification 5 is the one used to obtain second-stage estimates in our instrumentalvariable framework. 
to assume that parents gathered information on and chose between that school and the closest alternatives (i.e., this is the comparison that was made). Results using alternative spatial specifications and radiuses were closely aligned (table A6), as well as results from the same set of estimates without multiple imputation (table A7).

Consistent with descriptive statistics (table 3), being younger, having younger and married caregivers, and living in wealthier households were all associated with higher likelihoods of attending private preschools. ${ }^{13}$ Parameter estimates for wealth were remarkably stable across specifications, suggesting that a 10-point increase in the wealth index (0-100) was associated with an eight- (model 5) to 16- (model 2) percentage-point increase in the likelihood of choosing a private preschool. This suggests that financial barriers prevent some poor households from choosing private preschools (Akaguri 2014; Zuilkowski et al. 2018). Household resources and parental investments also predicted private-preschool choice. Parental school involvement positively and significantly predicted private-preschool choice across specifications, with each additional school-related activity undertaken by caregivers associated with a two- to four-percentage-point increase in the likelihood of private-preschool choice. The cognitive-stimulation index was an exception, as the estimated coefficient was negative and significant across most specifications. Further research is needed to shed light on this finding; we hypothesize that the negative association might be related to caregivers' expectations that private-sector KGs will provide better ECE than their public-sector counterparts, thereby reducing the need for at-home cognitive stimulation.

Coefficients of the preschool-, classroom-, teacher-, and head teacher-level indices were consistent with findings from the previous section, as better preschool facilities and more-motivated teachers were associated with higher and lower likelihoods of choosing private KG, respectively, with no associations between classroom resources and preschool choice. This is consistent with a recent study on the United States suggesting that parents used mostly structural aspects of schools to decide what "quality" was and that their perceptions of quality rarely matched the classroom process quality within the preschool (Bassok et al. 2018). Also, the head teacher-quality index was positively predictive of private preschool choice similarly to the preschool-resource index (but opposite with respect to the teacher-quality index).

Spatial information on neighboring preschools of the opposite type reinforced the index-related findings just discussed. First, the signs of the preschool, classroom, teacher, and head teacher indices for the closest preschool of the opposite type (negative, null, positive, negative, respectively) were reversed relative to those of the chosen preschool (positive, null, negative, positive),

\footnotetext{
${ }^{13}$ Estimates provide no evidence of gender differences. We also estimated models separately for boys and girls, and the only differences pertained to caregiver age and gender, which mattered more in terms of magnitude and statistical significance for girls' choice of private school.
} 
and exhibited comparable magnitudes. Second, if private preschools were chosen, estimates from model (5) suggested that a denser pool of neighboring preschools of the opposite type (i.e., public) was associated with a lower likelihood of attending private preschools - the opposite holds for denser pools of neighboring preschools of the same type. Specifically, a one-unit increase in the number of neighboring public (private) preschools was associated with a 3.8- (2.8-) percentage-point reduction (increase) in the likelihood of selecting private preschools. These magnitudes are in line with evidence from Kenya (Nishimura and Yamano 2013). The distances in walking time from the chosen preschools to the closest ones of the opposite type were not significant predictors of preschool choice. Nevertheless, table 4 provides supportive evidence that the spatial distribution of preschools and the characteristics of local preschool markets - both quality and quantity - were important determinants of preschool choice.

Research Question 3: Beyond Selection into Preschools, Do Household Characteristics Contribute to Children's School Readiness upon Preschool Entry and over One Preschool Year?

We next examined whether household resources played a role_-additional to entering the preschool-choice specification - in predicting children's school readiness skills at the start of the preschool year (eq. [2], table 5, panel A). As unobserved factors may have entered determination of preschool choice and school readiness, we used 2SLS, whereby preschool choice predicted from the first stage $(\widehat{\mathrm{PRI}})$ was used in the second stage to purge correlations with these unobserved factors. We predicted private-preschool choice based on the full specification in table 4 . The identifying instruments were distances to, the pool of, and other characteristics of preschools not chosen. A priori and within any model of test performance, it would seem that the number and characteristics of the preschools not chosen would not affect child outcomes at the time of entering kindergarten, or subsequently. The first-stage $F$-test for instruments' relevance was 19.69, far above the conventional threshold for weak instruments $(F<10)$.

We estimated four models for each domain: model (1) included predicted private-preschool (eq. [1]) and child characteristics; model (2) added caregiver characteristics; model (3) added household wealth; and model (4) added household resources and measures of parental involvement-cultural and social capital. Table 5 only reports results from model (4) on each outcome separately (the four stepwise models are in table A8). Note that the overidentification tests (Hansen J) for each of the models reported in table 5 were above critical values at conventional significance levels, providing no evidence to reject the null hypothesis that the instruments were orthogonal to the secondstage disturbance term.

Panel A (eq. [2]) offers a number of interesting results. First, predicted private preschool was associated with higher numeracy $(b=0.061 ; P<.01)$, 
TABLE 5

Start-of-Year (Fall) and Gain (Spring-Fall) in School Readiness, Second-Stage Estimates

\begin{tabular}{|c|c|c|c|c|c|c|c|c|}
\hline & \multicolumn{4}{|c|}{ A. Start-of-Year (Fall) Scores } & \multicolumn{4}{|c|}{ B. Change in Scores (Spring-Fall) } \\
\hline & EN & EL & $\mathrm{SE}$ & $\mathrm{EF}$ & EN & EL & SE & $\mathrm{EF}$ \\
\hline Private preschool (predicted) & $\begin{array}{l}.061^{* * *} \\
(.019)\end{array}$ & $\begin{array}{l}.075^{* * *} \\
(.022)\end{array}$ & $\begin{array}{l}.015 \\
(.021)\end{array}$ & $\begin{array}{l}.046^{*} \\
(.026)\end{array}$ & $\begin{array}{l}.017 \\
(.016)\end{array}$ & $\begin{array}{l}.059^{* * *} \\
(.019)\end{array}$ & $\begin{array}{c}-.009 \\
(.024)\end{array}$ & $\begin{array}{l}.010 \\
(.032)\end{array}$ \\
\hline \multicolumn{9}{|l|}{ Child characteristics: } \\
\hline Female & $\begin{array}{l}.007 \\
(.008)\end{array}$ & $\begin{array}{l}.016 \\
(.010)\end{array}$ & $\begin{array}{c}.006 \\
(.010)\end{array}$ & $\begin{array}{l}.008 \\
(.011)\end{array}$ & $\begin{array}{c}.002 \\
(.007)\end{array}$ & $\begin{array}{c}.014 \\
(.009)\end{array}$ & $\begin{array}{c}.014 \\
(.011)\end{array}$ & $\begin{array}{l}.005 \\
(.011)\end{array}$ \\
\hline Age & $\begin{array}{l}.056^{* * *} \\
(.004)\end{array}$ & $\begin{array}{l}.051^{* * *} \\
(.005)\end{array}$ & $\begin{array}{l}.041^{* * *} \\
(.005)\end{array}$ & $\begin{array}{l}.048^{* * *} \\
(.005)\end{array}$ & $\begin{aligned}-.000 \\
(.004)\end{aligned}$ & $\begin{aligned}-.003 \\
(.005)\end{aligned}$ & $\begin{aligned}-.005 \\
(.006)\end{aligned}$ & $\begin{array}{r}-.007 \\
(.006)\end{array}$ \\
\hline \multicolumn{9}{|l|}{ Caregiver characteristics: } \\
\hline Caregiver's age & $\begin{array}{l}.000 \\
(.000)\end{array}$ & $\begin{array}{l}.001 \\
(.001)\end{array}$ & $\begin{array}{l}.000 \\
(.001)\end{array}$ & $\begin{array}{c}-.000 \\
(.001)\end{array}$ & $\begin{array}{c}-.000 \\
(.001)\end{array}$ & $\begin{array}{c}-.000 \\
(.001)\end{array}$ & $\begin{array}{c}.001 \\
(.001)\end{array}$ & $\begin{array}{c}-.000 \\
(.001)\end{array}$ \\
\hline Caregiver is female & $\begin{array}{l}.016^{*} \\
(.009)\end{array}$ & $\begin{array}{l}.019^{*} \\
(.011)\end{array}$ & $\begin{array}{l}.007 \\
(.012)\end{array}$ & $\begin{array}{l}.002 \\
(.012)\end{array}$ & $\begin{array}{l}.005 \\
(.010)\end{array}$ & $\begin{array}{l}.009 \\
(.010)\end{array}$ & $\begin{array}{l}.007 \\
(.015)\end{array}$ & $\begin{array}{l}.018 \\
(.014)\end{array}$ \\
\hline Caregiver's education $>\mathrm{JHS}$ & $\begin{array}{l}.017^{*} \\
(.011)\end{array}$ & $\begin{array}{l}.010 \\
(.013)\end{array}$ & $\begin{aligned}-.008 \\
(.013)\end{aligned}$ & $\begin{array}{l}.003 \\
(.014)\end{array}$ & $\begin{array}{l}.010 \\
(.010)\end{array}$ & $\begin{array}{l}.012 \\
(.011)\end{array}$ & $\begin{array}{c}.003 \\
(.014)\end{array}$ & $\begin{array}{c}.021 \\
(.016)\end{array}$ \\
\hline Caregiver is married & $\begin{array}{l}.006 \\
(.011)\end{array}$ & $\begin{array}{l}.007 \\
(.013)\end{array}$ & $\begin{array}{l}-.020 \\
(.015)\end{array}$ & $\begin{array}{l}-.016 \\
(.015)\end{array}$ & $\begin{array}{l}.023^{* *} \\
(.011)\end{array}$ & $\begin{array}{l}.005 \\
(.012)\end{array}$ & $\begin{array}{c}-.000 \\
(.017)\end{array}$ & $\begin{array}{l}.021 \\
(.017)\end{array}$ \\
\hline $\begin{array}{l}\text { Household characteristics: } \\
\text { Wealth (poverty scorecard) }\end{array}$ & $\begin{array}{l}.002^{* * *} \\
(.000)\end{array}$ & $\begin{array}{l}.002^{* * *} \\
(.001)\end{array}$ & $\begin{array}{l}.001 \\
(.001)\end{array}$ & $\begin{array}{l}.000 \\
(.001)\end{array}$ & $\begin{array}{r}-.001^{*} \\
(.000)\end{array}$ & $\begin{array}{l}.000 \\
(.000)\end{array}$ & $\begin{aligned}-.000 \\
(.001)\end{aligned}$ & $\begin{array}{r}-.001 \\
(.001)\end{array}$ \\
\hline
\end{tabular}


Parental involvement:

Number of child's books ‘

Activities with child (index)

Help on homework

Parental involvement in school

(index)

Constant

$\begin{array}{lll}.001 & .003 & -.000 \\ (.002) & (.009) & (.002)\end{array}$

$\begin{array}{lll}.001 & (.002) & (.002) \\ .000 & -003)\end{array}$

$.000 \quad .007^{* * *}$

$\begin{array}{lr}.007^{* * *} & -.001 \\ (.003) & (.002)\end{array}$

-.001
$(.002)$

$-.002$

$\begin{array}{lll}.003) & (.003) & (.003)\end{array}$

$.010^{*}-.021^{* * *}$

(.004)

$\begin{array}{ll}.021 & .025^{* * *} \\ (.007) & (.007)\end{array}$

-.002
$(.006)$

(.002)

.003

(.003)

$-.007$

$.002-.004$

$\begin{array}{lll}.004 & .003 & -.001\end{array}$

$\begin{array}{llll}. .001 & .001 & .002 & .004\end{array}$

$(.004) \quad(.005)$

$\begin{array}{cccc} & -.123^{* * *} & -.151^{* * *} & .039 \\ & (.038) & (.046) & (.050)\end{array}$

$(.005)-(.004)$

$.170^{* * *}$ (.038)

$F$-test (first stage)

19.69

Hansen $J$ ( $P$-value

$.152 \quad .094$

.141

Observations

$\begin{array}{lll}.141 & .138 & .630 \\ 1,493 & 1,493 & 1,493\end{array}$

.630

.358

$(.004)$

$.169^{* * *}$

$.042)$

NoTE - Standard errors clustered at the preschool level. EN = early numeracy; EL = early literacy; SE $* P<.10$.

$$
\begin{aligned}
& * P<.10 \text {. } \\
& * * P<.05 \text {. }
\end{aligned}
$$


literacy $(b=0.075 ; P<.01)$, and executive function $(b=0.046 ; P<.1)$, but not with socioemotional scores. ${ }^{14}$ As KG1 children in the fall were entering their first year of kindergarten, we interpreted this evidence as reflecting the selection of children who were more advanced in cognitive skills into private preschools. Age was positively related to school readiness across all domains, suggesting that younger children were more likely to be sent to private preschools (table 4); yet, having conditioned on the type of preschool attended, older children performed better on school readiness. Household wealth was a strong predictor of academic school readiness outcomes beyond its influence on preschool choice. We hypothesize that these positive associations were driven by broader household availability of preschool-related resources other than books. ${ }^{15}$ Household resources and parental investments had significant associations too, with differences across domains. While the numbers of children's books in homes were positively associated with executive function $(b<$ $.007 ; P<.01)$, regular help on homework positively predicted all domains except executive function.

The key results from panel A suggest that there are independent associations between household and parental characteristics and start-of-year school readiness beyond the preschool sorting channel, mostly in the form of household resources and parental time commitments to children's education. Measures of parental engagement that were most predictive of private-preschool choice in table 4 cognitive stimulation and the parental involvement-were the weakest independent predictors of fall scores. Conversely, while regular help on homework predicted private-preschool choice to a weaker extent, it was the strongest predictor of children's fall school readiness. These findings stress the value of adopting heterogeneous measures of parental involvement and the importance of different types of investments and capital for children's outcomes.

Panel B in table 5 (eq. [3]) investigated whether private preschool affected children's outcomes - specifically, fall-to-spring change in scores-independent of differences in household characteristics. ${ }^{16}$ Results provide evidence of

\footnotetext{
${ }^{14}$ Table A10 reports the same set of analyses for the overall IDELA score computed as the mean of the four components. Panel A in table A10 suggests that predicted private preschool was associated with a higher total IDELA score $(b=0.049 ; P<.01)$, and both the number of books at home and regular help on homework were predictive of fall scores beyond the preschool selection channel $(b=0.003$; $P<.1$ and $b=0.015 ; P<0.01$, respectively).

15 The relationship between household possessions and children's academic achievement in Ghana is consistent with the findings of Chowa and colleauges (2013) for English (but not math) for much older children (16 years old, on average).

${ }^{16}$ In this model we did not control for start-of-year scores for two reasons. First, the dependent variable in panel $\mathrm{B}$ was constructed as the difference between end-of-year and start-of-year scores; hence the start-of-year information was included in the dependent variable. Second, including start-of-year scores as a regressor would introduce endogeneity that our identification strategy could not attenuate. Indeed, statistical tests were consistent with the geospatial information serving as a valid and relevant IV for KG preschool choice, yet less so for start-of-year scores. We nonetheless estimated models controlling for start-of-year scores (available upon request), and results were aligned, suggesting that even if endogeneity were an issue, it did not greatly affect the estimates.
} 
private-preschool effects only for literacy, confirming our hypothesis of selection effects in panel A. One year of private KG education led to improvement in overall literacy scores by 0.059 units $(P<.01)$, an approximately 32 percent increase, or about one-third (0.36) of a standard deviation change. Few of the other household variables in table 5 were consistently predictive of change in scores. Household wealth and parental involvement-books and help on homework - were negatively related to change in scores, suggesting greater improvements in school readiness among children from more-disadvantaged households, once the higher likelihood of choosing private preschools for children from wealthier households is controlled. Overall, the role of household resources and parental investments weakened across domains in these models, suggesting that parental investments mattered greatly for preschool selection and supporting children to be school-ready, yet attenuated once children entered KG1.

As a robustness check, we tested whether our results on change in scores were affected by the intervention that was implemented over the school year. We reestimated the same models in panel $\mathrm{B}$, controlling for treatment status with a dummy that equaled 1 if the preschool received an intervention and 0 if the preschool was a control. ${ }^{17}$ Results were consistent (table A11) and the coefficient of interest on predicted private preschool was virtually unchanged (early literacy: $b=0.060 ; P<.01$ ). This is consistent with the lack of differential impacts of the intervention on child outcomes by preschool type (Wolf et al. 2019).

\section{Summary and Conclusion}

This study examined differences in public and private kindergrtens in Ghana, and the role of child, household, and preschool characteristics in predicting public versus private preschool choices and children's school readiness. We attempted to disentangle relative direct contributions of household characteristics (controlling for private-preschool choice) and of privatepreschool choice as determinants of children's school readiness. We used novel spatial information on between-preschool distances and longitudinal data of direct assessments for children in their first year of kindergarten.

We found public-private differences in child, household, and preschool characteristics, the majority of which favored private preschools. Children enrolled in private preschools scored higher at enrollment in three of four domains and came from wealthier, smaller, and more resource-endowed families. Therefore, much of the observed score variation seems a reflection of greater home investment and socioeconomic background. Private preschools

\footnotetext{
${ }^{17}$ Adding treatment status as an additional predictor was unlikely to introduce endogeneity given its randomized nature.
} 
had better facilities and head teacher quality, but no differences in classroom facilities, and public preschools had higher teacher quality. As such, our findings align with existing studies in Ghana and elsewhere that documented less-experienced and less-qualified teachers yet less teacher absenteeism, more resources, and better child outcomes in private schools (Alderman et al. 2001; Tooley et al. 2007; Mbiti 2016; Zuilkowski et al. 2018).

Moreover, we found that parental characteristics were associated with children's school readiness as they entered preschool, beyond their influence on preschool choices. The number of books at home and help on homeworktwo variables that may proxy for cultural and social capital, respectively - were most predictive of school readiness upon preschool entrance, suggesting that investments in children go beyond simply selecting the type of preschool presumed to be best and that inequality in parental investments starts early in children's lives, before entering preschool. However, the predictive role of different forms of capital weakened as children were exposed to preschool for the year. Our findings on learning over the school year documented robust and statistically significant associations between private-KG attendance and early literacy outcomes. Conversely, there was no effect of private-KG education on other school readiness domains. These findings - novel at the preschool levelalign with the analysis of Wamalwa and Burns (2018), who documented substantial literacy and numeracy gains from private-school attendance independent of school choice for children in lower primary grades in Kenya. Yet the findings contrast with Lucas and Mbiti (2014), who found that selection effects (students entering with already higher scores due to observed and unobserved factors such as indidual ability and parental motivation) rather than attendance of a specific type of school explained value-added test score gains across Kenyan secondary schools. This mixed evidence from different stages of schooling seems suggestive of existing private-school effects that weaken as children progress through grades. ${ }^{18}$

Our study advanced knowledge in several ways. First, this study was unique in its focus on roles of household resources on kindergarten outcomes. Relatively little is known about how families cope with economic hardship and prepare their children for school across LMICs. Similarly, limited evidence exists on KG-educational effectiveness in enhancing school readiness in subSaharan Africa. That parental investments were related to private kindergarten choice and to school readiness has important implications for early childhood development policy and the study of educational inequality. On the one hand, as parental investments are a function of household wealth-and wealthier households are more likely to be resource endowed and to engage in cognitively stimulating activities - the risk of exacerbating socioeconomic inequalities

\footnotetext{
18 Consistent with the above evidence from sub-Saharan Africa, Singh (2015) also found evidence of sizable private-school effects $(>0.5 \mathrm{SD})$ on English scores (but not math) for primary-school children in rural India, but more modest effects $(<0.2 \mathrm{SD})$ for secondary-school children.
} 
upon $\mathrm{KG}$ entrance is evident. By the same token, since better-resourced households tend to send their children to private preschools, the growth of the private sector may hinder social mobility and facilitate the persistence of socioeconomic status. On the other hand, the finding that one year of $\mathrm{KG}$ improved literacy outcomes, and that changes were more marked for children living in less-wealthy households and households with less cultural and social capital, points to roles of schools in reducing early disparities. Documenting these positive associations is of great importance in light of massive investments in ECE that are occurring globally. Policies may consider targeting increased private-KG access for poorer households, for instance, through vouchers and strengthening the quality and quantity of public kindergartens. Overall, the study suggests that making KG education more widely available and more accessible to all households is likely to reduce inequality.

Study limitations lay the ground for subsequent research. First, the measures of parental investments in each household were all caregiver-reported, were based on answers to structured questions, and were likely not fully representative of all ways that Ghanaian caregivers invest in their children. In particular, the activities with child index lacked specificity in terms of frequency, diversity, and quality of activities. Interaction quality, rather than quantity, has been shown to predict low-income children's school readiness in other contexts (Connell and Prinz 2002). Additional work using more robust and objective metrics of parental investments would be valuable. Second, data on caregivers were obtained through a phone survey with only two-thirds of caregivers. Although we used multiple imputation to account for missing data on caregiver information, results should be interpreted with caution. Third, endogeneity might remain a concern when making causal claims of the findings. The spatial identification strategy used, together with longitudinal data on child outcomes, was a step in the direction of addressing endogeneity, yet a causal interpretation is not indisputable. Finally, although this study used a diverse sample of children living in the Greater Accra Region of Ghana, the findings may not generalize beyond this context. More work is needed to explore analogous research questions in diverse cultural, linguistic, and geographical contexts.

\section{References}

Akaguri, Luke. 2014. "Fee-Free Public or Low-Fee Private Basic Education in Rural Ghana: How Does the Cost Influence the Choice of the Poor?" Compare 44 (2): 14061.

Akyeampong, Kwame. 2009. "Public-Private Partnership in the Provision of Basic Education in Ghana: Challenges and Choices." Compare 39 (2): 135-49.

Alderman, Harold, Peter Orazem, and Elizabeth Paterno. 2001. "School Quality, School Cost, and the Public/Private School Choices of Low-Income Households in Pakistan." Journal of Human Resources 36 (2): 304-26. 
Altonji, Joseph, Todd Elder, and Christopher Taber. 2005. "Selection of Observed and Unobserved Variables: Assessing the Effectiveness of Catholic Schools." Journal of Political Economy 113 (1): 151-84.

Bassok, Daphna, Anna Markowitz, Daniel Player, and Michelle Zagardo. 2018. "Are Parents' Ratings and Satisfaction with Preschools Related to Program Features?" AERA Open 4 (1): 1-17.

Baum, Donald, Husein Abdul-Hamid, and Hugo Wesley. 2018. "Inequality of Educational Opportunity: The Relationship between Access, Affordability, and Quality of Private Schools in Lagos, Nigeria." Oxford Review of Education 44 (4): 459-75.

Baum, Donald, Laura Lewis, Oni Lusk-Stover, and Harry Anthony Patrinos. 2014. "What Matters Most for Engaging the Private Sector in Education: A Framework Paper.” Systems Approach for Better Education Results (SABER) Working Paper no. 8, World Bank, Washington, DC.

Behrman, Jere R., Patrice Engle, and Lia C. Fernald. 2014. "Preschool Programs in Developing Countries." In Education Policy in Developing Countries, ed. Paul Glewwe. Chicago: University of Chicago Press.

Berlinski, Samuel, and Norbert Schady. 2015. "More Bang for the Buck: Investing in Early Childhood Development." In The Early Years. Child Well-Being and the Role of Public Policy, ed. Samuel Berlinski and Norbert Schady. New York: Palgrave Macmillan.

Bianchi, Suzanne, and John Robinson. 1997. "What Did You Do Today? Children's Use of Time, Family Composition, and the Acquisition of Social Capital." Journal of Marriage and Family 59 (2): 332-44.

Bidwell, Kelly, and Loïc Watine. 2014. Exploring Early Education Programs in Peri-Urban Settings in Africa: Final Report. New Haven, CT: Innovations for Poverty Action.

Bradley, Robert, and Diane Putnick. 2012. "Housing Quality and Access to Material and Learning Resources within the Home Environment in Developing Countries." Child Development 83 (1): 76-91.

Britto, Pia, Hirokazu Yoshikawa, and Kimberly Boller. 2011. "Quality of Early Childhood Development Programs in Global Contexts: Rationale for Investment, Conceptual Framework and Implications for Equity." Social Policy Report 25 (2): 1-31.

Central Intelligence Agency. 2017. "Ghana." In The World Factbook. Accessed September 20, 2017. https:/ /www.cia.gov/library/publications/the-world-factbook/geos /gh.html.

Chowa, Gina, Rainier Masa, Christopher J. Wretman, and David Ansong. 2013. "The Impact of Household Possessions on Youth's Academic Achievement in the Ghana Youthsave Experiment: A Propensity Score Analysis." Economics of Education Review 33:69-81.

Chudgar, Amita, and Elizabeth Quin. 2012. "Relationship between Private Schooling and Achievement: Results from Rural and Urban India." Economics of Education Review 31 (4): 376-90.

Connell, Christian, and Ronald Prinz. 2002. "The Impact of Childcare and ParentChild Interactions on School Readiness and Social Skills Development for LowIncome African American Children.” Journal of School Psychology 40 (2): 177-93.

Cox, Donald, and Emmanuel Jimenez. 1990. "The Relative Effectiveness of Private and Public Schools. Evidence from Two Developing Countries." Journal of Development Economics 34 (1-2): 99-121. 
Dixon, Pauline, and James Tooley. 2012. "A Case Study of Private Schools in Kibera: An Update." Educational Management Administration E Leadership 40 (6): 690706.

Filmer, Deon, and Lant Pritchett. 2001. "Estimating Wealth Effects without Expenditure Data — or Tears: An Application to Educational Enrollment in States of India." Demography 38 (1): 115-32.

Ghana Education Service. 2012. "Programme to Scale-Up Quality Kindergarten Education in Ghana." Ghana Ministry of Education, Accra. Accessed September 11, 2017. https://issuu.com/sabretom/docs/10_12_12_final_version_of_narrative_op.

Ghana Ministry of Education. 2016. Education Sector Performance Report, 2016. Accra: Ghana Ministry of Education.

Glewwe, Paul, and Hanan Jacoby. 1994. "Student Achievement and Schooling Choice in Low-Income Countries: Evidence from Ghana.” Journal of Human Resources 29 (3): 843-64.

Glewwe, Paul, and Harry Patrinos. 1999. "The Role of the Private Sector in Education in Vietnam: Evidence from the Vietnam Living Standards Survey." World Development 27 (5): 887-902.

Härmä, Joanna. 2009. "Can Choice Promote Education for All? Evidence from Growth in Private Primary Schooling in India." Compare 39 (2): 151-65.

Heyneman, Stephen, and Jonathan Stern. 2014. "Low Cost Private Schools for the Poor: What Public Policy Is Appropriate?” International Journal of Educational Development 35:3-15.

Howes, Carollee, Jolena James, and Sharon Ritchie. 2003. "Pathways to Effective Teaching." Early Childhood Research Quarterly 18 (1): 104-20.

Jones, Sam. 2016. "How Does Classroom Composition Affect Learning Outcomes in Ugandan Primary Schools?" International Journal of Educational Development 48: 66-78.

Kabay, Sarah, Sharon Wolf, and Hirokazu Yoshikawa. 2017. "So That His Mind Will Open': Parental Perceptions of Early Childhood Education in Urbanizing Ghana." International Journal of Educational Development 57:44-53.

Lareau, Annette. 1989. "Family-School Relationships: A View from the Classroom." Educational Policy 3:245-59.

Lareau, Annette, and Elliot Weininger. 2003. "Cultural Capital in Educational Research: A Critical Assessment." Theory and Society 32:567-606.

Lewis, Laura. 2013. "Is There a Role for the Private Sector in Education?" Education for Global Development. Accessed September 29, 2017. https://blogs.worldbank.org /education/europeandcentralasia/there-role-private-sector-education.

Lucas, Adrienne, and Isaac Mbiti. 2014. "Effects of School Quality on Student Achievement: Discontinuity Evidence from Kenya." American Economic Journal: Applied Economics 6 (3): 234-63.

Mbiti, Isaac. 2016. "The Need for Accountability in Education in Developing Countries." Journal of Economic Perspectives 30:109-32.

McCoy, Dana Charles, Evan Peet, Majid Ezzati, Goodarz Danaei, Maureen Black, et al. 2017. "Early Childhood Developmental Status in Low-and Middle-Income Countries: National, Regional, and Global Prevalence Estimates Using Predictive Modeling." PLoS Medicine 14 (1): e1002233. 
McNeal, Ralph, Jr. 1999. "Parental Involvement as Social Capital: Differential Effectiveness on Science Achievement, Truancy, and Dropping Out." Social Forces 78 (1): $117-44$.

Muralidharan, Karthik, and Venkatesh Sundararaman. 2015. "The Aggregate Effect of School Choice: Evidence from a Two-Stage Experiment in India." Quarterly Journal of Economics 130 (3): 1011-66.

Nishimura, Mikiko, and Takashi Yamano. 2013. "Emerging Private Education in Africa: Determinants of School Choice in Rural Kenya." World Development 43:266-75.

Nsiah-Peprah, Yaw. 2004. "Assessment of the Role of Private Schools in the Development of Education in Ghana: A Study of the Kumasi Metropolis." Journal of Science and Technology 24 (2): 54-76.

OECD. 2012. Public and Private Schools: How Management and Funding Relate to Their SocioEconomic Profile. Paris: OECD.

Oketch, Moses, Maurice Mutisya, Moses Ngware, and Alex Ezeh. 2010. "Why Are There Proportionately More Poor Pupils Enrolled in Non-state Schools in Urban Kenya in Spite of FPE Policy?" International Journal of Educational Development 30 (1): 23-32.

Oketch, Moses, and Moses Ngware. 2010. "Free Primary Education Still Excludes the Poorest of the Poor in Urban Kenya." Development in Practice 20 (4-5): 603-10.

Patrinos, Harry Anthony, Felipe Barrera-Osorio, and Juliana Guáqueta. 2009. The Role and Impact of Public-Private Partnerships in Education. Washington, DC: World Bank.

Phillips, Deborah, Debra Mekos, Sandra Scarr, Kathleen McCartney, and Martha Abbott-Shim. 2000. "Within and Beyond the Classroom Door: Assessing Quality in Child Care Centers." Early Childhood Research Quarterly 15 (4): 475-96.

Pisani, Lauren, Ivelina Borisova, and Amy Jo Dowd. 2018. "Developing and Validating the International Development and Early Learning Assessment (IDELA)." International Journal of Educational Research 91:1-15.

Republic of Ghana. 2015. Education Management Information System: Report on Basic Statistics and Planning Parameters for Basic Education in Ghana 2014/2015. Accessed June 27, 2017. http://www.moe.gov.gh/emis/html/basic.htm.

Schreiner, Mark, and Gary Woller. 2010. "Simple Poverty Scorecard: PovertyAssessment Tool Ghana.” Accessed December 26, 2019. http://www.simplepoverty scorecard.com/GHA_2012_ENG.pdf.

Siddiqui, Nadia. 2017. "Parental Education as a Determinant of School Choice: A Comparative Study of School Types in Pakistan." Research in Education 99 (1): 318.

Sieben, Swen, and Clemens M. Lechner. 2019. "Measuring Social Capital through the Number of Books in the Household.” Measurement Instruments for the Social Sciences 2 (1). https://link.springer.com/article/10.1186/s42409-018-0006-0.

Singh, Abhijeet. 2014. "Test Score Gaps between Private and Government Sector Students at School Entry Age in India.” Oxford Review of Education 40 (1): 30-49.

Singh, Abhijeet. 2015. "Private School Effects in Urban and Rural India: Panel Estimates at Primary and Secondary School Ages." Journal of Development Economics 113:16-32.

Slot, Pauline, Paul Leseman, Josje Verhagen, and Hanna Mulder. 2015. "Associations between Structural Quallity Aspects and Process Quality in Dutch Early Childhood Education and Care Settings." Early Childhood Research Quarterly 33 (4): 64-76. 
Somers, Marie-Andrée, Patrick J. McEwan, and J. Douglas Willms. 2004. "How Effective are Private Schools in Latin America?" Comparative Education Review 48 (1): 48-69.

Tooley, James. 2005. "Private Schools for the Poor." Education Next: A Journal of Opinion and Research 5 (4): 22-32.

Tooley, James, Pauline Dixon, and Isaac Amuah. 2007. "Private and Public Schooling in Ghana: A Census and Comparative Survey." International Review of Education 53 (4): 389-415.

Tooley, James, Pauline Dixon, and Olanrewaju Olaniyan. 2005. "Private and Public Schooling in Low-Income Areas of Lagos State, Nigeria: A Census and Comparative Survey." International Journal of Educational Research 43 (3): 125-46.

UNESCO. 2015a. EFA Global Monitoring Report 2015, Education for All: Achievements and Challenges. Accessed September 8, 2017. http://unesdoc.unesco.org/images/0023 /002322/232205e.pdf.

UNESCO. 2015b. The Privatization of Education in Developing Countries. Evidence and Policy Implications. Accessed June 28, 2018. http://unesdoc.unesco.org/images/0024 /002438/243824e.pdf.

UNESCO and Brookings. 2013. Toward Universal Learning: Recommendations from the Learning Metrics Task Force. Montreal: UNESCO Institute for Statistics; Washington, DC: Center for Universal Education at the Brookings Institution.

United Nations. 2000. United Nations Millennium Declaration. New York: United Nations.

United Nations. 2015. Transforming Our World: The 2030 Agenda for Sustainable Development. New York: United Nations.

Vandell, Deborah. 2004. "Early Child Care: The Known and the Unknown." MerrillPalmer Quarterly 50 (3): 387-414.

Wamalwa, Fredrick, and Justine Burns. 2018. "Private Schools and Student Learning Achievements in Kenya." Economics of Education Review 66:114-24.

Wolf, Sharon, J. Lawrence Aber, Jere R. Behrman, and Edward Tsinigo. 2019. "Experimental Impacts of the 'Quality Preschool for Ghana' Interventions on Teacher Professional Well-Being, Classroom Quality, and Children's School Readiness.” Journal of Research on Educational Effectiveness 12 (1): 10-37.

Wolf, Sharon, Peter Halpin, Hirokazu Yoshikawa, Amy Jo Dowd, Lauren Pisani, and Ivelina Borisova. 2017. "Measuring School Readiness Globally: Assessing the Construct Validity and Measurement Invariance of the International Development and Early Learning Assessment (IDELA) in Ethiopia." Early Childhood Research Quarterly 41 (4): 21-36.

Wolf, Sharon, and Dana Charles McCoy. 2019. "Household Socioeconomic Status and Parental Investments: Direct and Indirect Relations with School Readiness in Ghana." Child Development 90 (1): 260-78.

Wolf, Sharon, Mahjabeen Raza, Sharon Kim, J. Lawrence Aber, Jere R. Behrman, and Edward Seidman. 2018. "Measuring and Predicting Process Quality in Ghanaian Preprimary Classrooms Using the Teacher Instructional Practices and Processes System." Early Childhood Research Quarterly 45 (4): 18-30.

$\mathrm{Xu}$, Jun, and Gillian Hampden-Thompson. 2012. "Cultural Reproduction, Cultural Mobility, Cultural Resources, or Trivial Effect? A Comparative Approach 
PESANDO ET AL.

to Cultural Capital and Educational Performance." Comparative Education Review 56 (1): 98-124.

Zuilkowski, Stephanie, Benjamin Piper, Salome Ong'ele, and Onesmus Kiminza. 2018. "Parents, Quality, and School Choice: Why Parents in Nairobi Choose Low-Cost Private Schools over Public Schools in Kenya's Free Primary Education Era." Oxford Review of Education 44 (2): 258-74. 